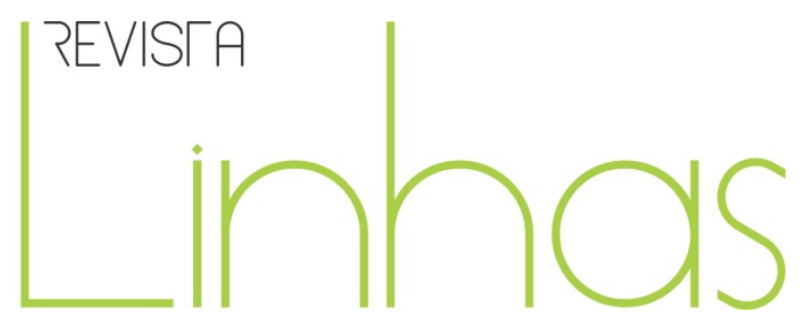

\title{
Escolas isoladas paulistas: um modelo desajustado?
}

\section{Resumo}

Este artigo tem por objetivo analisar a história das escolas isoladas paulistas no período de 1893 a 1932, fundamentando-se no método histórico-crítico. Para tanto, foi realizada uma pesquisa bibliográfica tendo como referência teórica os trabalhos de Saviani $(2007,2008)$; Marcílio (2005); (1999); Souza (1998, 2006, 2009); Reis Filho (1995); Infantosi (1983) e Nagle (1974). Os documentos, impressos e manuscritos, constantes no Arquivo do Estado de São Paulo foram as fontes primárias consultadas. No primeiro período republicano, a necessidade de universalização da instrução pública levou à criação dos grupos escolares, que atendiam, inicialmente, aos grandes centros urbanos; para os centros menores e os bairros populosos criaram-se as escolas reunidas. Nos bairros periféricos, nas vilas e áreas rurais foram adotadas as escolas isoladas, cuja função era dar uma formação básica - leitura, escrita e as operações elementares da aritmética - à população pobre, residente nesses locais. A organização do trabalho didático, nessas escolas, se aproximava da organização adotada nas escolas de primeiras letras sob o método mútuo do Período Imperial. A história das escolas isoladas é marcada pelos aspectos da moderna escola burguesa, especialmente suas antecessoras, as escolas de primeiras letras. Funcionando em casebres, herdaram das escolas de primeiras letras principalmente o atendimento, em uma só sala, de crianças em diferentes níveis de adiantamento.

Palavras-chave: História da educação. Instituições escolares. Escolas isoladas paulistas.

\section{Maria Angélica Cardoso}

Doutorado em Filosofia e História da Educação pela Universidade Estadual de Campinas - UNICAMP. cardoso_angelica@hotmail.com

\section{Para citar este artigo:}

CARDOSO, Maria Angélica. Escolas isoladas paulistas: um modelo desajustado? Revista Linhas, Florianópolis, v. 14, n. 27, jul./dez. 2013. p. $201-233$.

\section{DOI: $10.5965 / 1984723814272013201$}

http://dx.doi.org/10.5965/1984723814272013201 


\title{
Schools isolated in São Paulo: a model misfit?
}

\begin{abstract}
This article aims to analyze the history of isolated schools in São Paulo in the period from 1893 to 1932, taking account of the historical-critical method. Therefore, we performed a bibliographic research using as a theoretical reference the work of Saviani (2007, 2008), Marcílio (2005) (1999, Souza (1998, 2006, 2009); Reis Filho (1995); Infantosi (1983), and Nagle (1974). Printed documents and manuscripts contained in the State Archive of São Paulo were the primary sources consulted. In the first Republican period, the necessity of a universal public education resulted in the creation of school groups, which met initially the major urban centers, to smaller centers and crowded quarters were set up schools gathered. In the suburbs, in towns and rural areas were adopted isolated schools whose function was to provide a basic training - reading, writing and elementary operations of arithmetic - the poor population residing in these locations. The organization of the teaching work in these schools, approached the organization adopted in the schools of first letters the method mutual in Imperial Period. The history of isolated schools is marked by aspects of modern bourgeois school, especially its predecessors, the schools first letters. Working in shacks, they inherited the school of first letters, especially the service in one room, children at different levels of progress.
\end{abstract}

Keywords: Education History. School Institutions. Isolated Schools Paulistas. 


\section{Escolas isoladas paulistas: um modelo desajustado?}

Na primeira década da República, a instrução paulista compunha-se de um mosaico de escolas ${ }^{2}$. As escolas primárias do final do Império evoluíram para escolas preliminares que, junto com suas auxiliares - escolas intermédias e escolas provisórias seriam responsáveis pela educação dos menores de ambos os sexos, dos 7 aos12 anos de idade. Além dessas modalidades, havia também as escolas mistas, as ambulantes e as noturnas, estas responsáveis pela instrução dos adultos analfabetos. A partir de 1893, o mosaico ganhou novas peças: os grupos escolares e as escolas reunidas.

A partir daí, a expressão escola isolada foi substituindo, gradativamente, as denominações escolas preliminares, escolas provisórias e escolas intermédias.

\section{As escolas isoladas}

Sobre as escolas isoladas, Infantosi (1983, p. 91) escreve que, ao se proclamar a República, os únicos estabelecimentos de ensino primário eram:

[...] as escolas preliminares, unidades escolares não agrupadas, em que um professor ministrava a instrução para crianças de diversas idades e de avanço escolar heterogêneo. Depois de 1894, quando foram criados os primeiros grupos escolares, e para deles distinguirem, aqueles estabelecimentos passaram a denominar-se escolas isoladas.

Na expressão de Rossi (2008, p. 153), “as escolas isoladas representavam um outro momento da educação e, comparadas aos grupos escolares, parecem desajustadas diante da racionalização e controle do trabalho nos grupos". Essas escolas, explicita a autora, não eram isoladas apenas por serem classes autônomas, mas pela característica de funcionamento unitário. Enquanto os grupos escolares e as escolas reunidas se caracterizavam pelo agrupamento de escolas elementares, aquelas se mantinham autônomas, unitárias. As escolas isoladas pareciam desajustadas frente aos grupos escolares, que possuíam várias salas de aulas, com um professor por classe e alunos

\footnotetext{
${ }^{1}$ Pesquisa de doutoramento financiada pela CAPES.

${ }^{2}$ Expressão utilizada por Dallabrida no título do livro - Mosaico de Escolas: modos de educação em Santa Catarina na Primeira República.
} 
agrupados segundo a idade correlacionada à série. Sua precariedade as afastava dos modernos processos pedagógicos e da organização administrativa dos grupos escolares, estabelecimentos muito superiores a elas.

A primeira vez que o termo escola isolada apareceu na legislação paulista foi no Regimento Interno das Escolas Públicas - Decreto 248, de 26 de julho de 1894:

Artigo 82. - Cada Grupo Escolar poderá comportar a lotação de 4 a 10 escolas isoladas no máximo e será regida por tantos professores quantos forem os grupos de 40 alunos e pelos adjuntos que forem necessários à diretoria.

Artigo 85. - Em suas relações com o Governo, com o Conselho Superior ou com o Diretor Geral, os diretores se dirigirão sempre por intermédio do inspetor do distrito, que exercerá sobre os Grupos Escolares as mesmas funções conferidas por lei em relação às escolas isoladas. (SÃO PAULO, 1894).

A legislação anterior a 1904, embora citasse o termo escolas isoladas, mantinha as adjetivações preliminar, intermédia e provisória. Em 1904, a Lei nº 930 e o Decreto $n^{\circ} 1.239$ modificaram várias disposições em vigor na instrução pública paulista. A partir daí, mudaram-se as denominações de escola preliminar, escola intermédia e escola provisória para escola isolada. No artigo $1^{\circ}$, ficou determinado que o ensino público preliminar fosse ministrado em:

I Escolas ambulantes ${ }^{3}$;

II Escolas isoladas situadas em bairros ou sedes de distritos de paz;

III Escolas isoladas situadas nas sedes dos municípios;

IV Grupos Escolares;

$\checkmark$ Escola-Modelo anexa à Escola Normal da Capital e Jardim da Infância (SÃO Paulo, 1904b).

A localização das escolas isoladas deveria atender à conveniência da disseminação do ensino e à importância do núcleo de população escolar.

\footnotetext{
${ }^{3}$ Esse nome designava as escolas que atendiam de forma intercalada - uma semana em um bairro, outra semana noutro - aos locais onde o número de crianças era baixo. Era um "meio de aproveitar os esforços de um só professor em diferentes pontos de população disseminada" (GUIMARAES, 1894).
} 
O artigo 30, do Decreto 1.239 (SÃO PAULO, 1904b), rezava que o ensino na escola modelo, nos grupos escolares e nas escolas isoladas seria distribuído por quatro anos. Nas escolas ambulantes, por três anos.

O Artigo $4^{\circ}$ da Lei $n^{\circ} 930$ (SÃO PAULO, 1904a) estabelece que “o poder executivo fará a revisão dos programas de ensino preliminar, de modo que na distribuição das matérias se atenda o desenvolvimento intelectual dos alunos e se observem os princípios do método intuitivo." Pelo Decreto 1.239 (SÃO PAULO, 1904b), "os programas de ensino serão os que o Governo determinar e organizados pelo inspetor geral do ensino. Os programas adaptados serão uniformemente observados na escola-modelo, nos grupos escolares e nas escolas isoladas" (Artigo 31).

Quinze anos após a criação dos grupos escolares, em 1907, o inspetor geral do ensino, João Lourenço Rodrigues, realizou um levantamento sobre a instrução no estado de São Paulo e concluiu que a organização do ensino se mantinha estável, ainda que lhe faltasse uniformidade. Em 1897, a Lei n 520 buscava, conforme o inspetor geral, dar organização regular e uniforme ao ensino público primário, tanto da capital como do interior, mas não foi essa a interpretação dada à lei; por isso, a metodização definitiva do ensino público ficou relegada a plano secundário. Para João Lourenço, foram "nove anos perdidos [1897 a 1906], nove anos de estacionamento, senão de recuo, na obra da reorganização do ensino paulista" ${ }^{4}$. Em 1908, escrevia que eram raras "as escolas em que se praticavam os modernos processos de ensino". A situação, posteriormente, se agravou ainda mais com o aumento das escolas: em 1898, eram 36 grupos escolares e 600 escolas isoladas; em 1906, duplicou o número de grupos escolares e o número de escolas isoladas não estava longe de 1.000. "Com este aumento tão rápido das nossas instituições de ensino, impossível se tornava dar a todas elas uma organização uniforme, perfeita, definitiva, quer pelo lado material, quer, sobretudo, pelo lado pedagógico" 5 . Era tempo, então, de tratar da inspeção escolar, trabalho que daria uniformidade ao ensino tanto nos grupos escolares quanto nas escolas isoladas. Para o inspetor geral, organização e inspeção eram dois elementos distintos na administração escolar, mas

\footnotetext{
${ }^{4}$ Anuário do Ensino do Estado de São Paulo. 1907-1908, p. 67.

${ }^{5}$ Ibid. p. 68.
} 
solidários e conexos. "A organização é o elemento dinâmico, a inspeção é o elemento estático. Esta representa a ordem, aquela o progresso. [...] Uma cria, organiza; outra conserva" 6 .

Mas as condições das escolas isoladas eram precárias. Em 1906, funcionavam, na capital do estado, 129 escolas isoladas, 43 das quais para o sexo masculino, 52 para o sexo feminino e 34 mistas, totalizando 4.332 matrículas, com uma frequência de $85 \%$, isto é, 3.709 frequentes. ${ }^{7}$ A frequência parece satisfatória, dizia o inspetor, porém tratava-se da frequência em dia de exame. A frequência ordinária alcançava uma porcentagem bem menor, afirmava ele. Conforme os relatórios dos inspetores escolares, os resultados dos exames não foram satisfatórios, dada a precariedade de funcionamento da maioria, talvez mesmo da totalidade, das escolas isoladas da capital. Quanto à organização, havia "uma incompreensível falta de uniformidade, quer no ensino, quer na disciplina das escolas isoladas"8. Dado o estado deplorável, estas escolas exigiam medidas diferenciadas e urgentes para a qual João Lourenço tinha uma proposta, pautando-se em dois procedimentos básicos: a criação de uma escola isolada modelo, já que as condições das escolas isoladas eram muito diversas das condições dos grupos escolares, para os quais já existiam as escolas-modelo; e a criação de uma categoria de inspetores inspetores residentes - que teriam o encargo de organizar e inspecionar as escolas isoladas dos respectivos distritos. Os atuais inspetores tomariam o nome de diretores de ensino, ou inspetores centrais, os quais dentre outros encargos, seriam encarregados da organização e inspeção dos grupos escolares ${ }^{9}$.

Em 1908, o Decreto n 1.577, de 21 de fevereiro, criava a Escola Isolada Modelo que, anexa à Escola Normal, serviria de padrão para a organização das escolas isoladas. $\mathrm{O} \S 2^{\circ}$ do Artigo $1^{\circ}$ determinava:

[...] o diretor da Escola Normal, depois da necessária experiência, submeterá à aprovação do Governo o plano do Regimento Interno dessa nova Escola, seu programa, horário, etc., que, mais tarde, serão adotados

\footnotetext{
${ }^{6}$ Ibid. p. 48.

7 Ibid. p. 87.

${ }^{8}$ Ibid. p. 68.

${ }^{9}$ Ibid., p. 68.
} 
em todas as escolas isoladas do Estado, para um trabalho de remodelação definitiva de todas elas (SÃO PAULO, 1908).

A Escola Isolada Modelo foi instalada oficialmente no dia 29 de abril de 1908. Achavam-se matriculadas 91 crianças, sendo 46 meninas e 45 meninos, estudando:

Leitura. Linguagem. Números. Caligrafia. Geografia. História Pátria. Animais. Plantas. Lições Gerais. Desenho. Música. Trabalho Manual. Ginástica.

O limite a que deve atingir cada uma das matérias acima discriminadas somente poderá ser demarcado ao encerrar-se o ano letivo atual, quando já estiverem colhidos e apreciados os ensinamentos de experiências e da observação quotidiana. ${ }^{10}$

Ela funcionava em dois prédios contíguos, com duas classes, uma para cada sexo, oferecendo amplas acomodações e preenchendo todos os requisitos pedagógicos. Cabe recordar que a realidade das escolas isoladas era bem diferente: funcionavam em salas acanhadas e não dispunham dos requisitos pedagógicos para o ensino efetivo.

No ano em que fora criada a Escola Isolada Modelo havia, no estado de São Paulo, 1.276 escolas isoladas, sendo 1.139 no interior e 137 na Capital. Em 1906, nos 34 municípios que enviaram os dados estatísticos havia 29.543 alunos matriculados, cabendo 15.179 à seção masculina e 14.364 à seção feminina. O inspetor João Lourenço considerava mais precisos os dados de 1907, que contabilizavam 1.111 escolas isoladas, sendo 511 do sexo masculino, 437 do sexo feminino e 163 mistas, nas quais estavam matriculados 17.473 meninos e 17.450 meninas. ${ }^{11}$

O ano seguinte ao da criação da Escola Isolada Modelo foi de observação e coleta de experiências para a elaboração do regulamento, do programa e dos horários que, em 1910, já estavam nas mãos do secretário do Interior. O diretor geral do ensino aguardava a aprovação, pois “só depois desse ato empreenderá a Diretoria Geral a reorganização das escolas isoladas pelo tipo proposto pela Escola Isolada Modelo" (OSCAR THOMPSON, Diretor Geral da Instrução Pública ${ }^{12}$ ).

\footnotetext{
${ }^{10}$ Ibid. p. 122.

${ }^{11}$ Ibid. p. 35.

${ }^{12}$ Id., 1909-1910, p. 35.
} 
$\mathrm{O}$ ato desdobrou-se em decretos que foram promulgados em 13 de fevereiro de 1911, sob os números 2.004 e 2.005. O primeiro, aprovava o Regimento Interno das Escolas Isoladas Modelo, anexas à Escola Normal de São Paulo; e o segundo, aprovava e mandava observar o programa de ensino para as escolas isoladas do estado.

No entanto, os anos que se seguiram à criação da Escola Isolada Modelo não trouxeram mudanças significativas na organização das escolas isoladas:

As condições pouco favoráveis dos prédios onde funcionam, a insuficiência de material, os defeitos de metodização, os vícios na transmissão de conhecimentos, a má interpretação de programas e outras pequenas causas, são obstáculos que ainda não foram removidos, pelo menos em absoluto, constituindo isto os principais embaraços que impedem a boa marcha do ensino.

O programa de ensino baixado com o Decreto no 2005 de 13 de fevereiro de 1911, mais prático e exequível que o então seguido veio, em parte, sanar dificuldades, porém por poucos tem sido compreendido (REIS JUNIOR, 1910-1911).

A má interpretação do programa ocorria, conforme os inspetores de escola, porque somente os professores da capital frequentavam a Escola Isolada Modelo. Os professores do interior não tinham nenhuma condição: seus vencimentos eram menores até mesmo do que o dos professores adjuntos dos grupos escolares e eles já tinham que arcar com o aluguel das casas onde funcionavam suas escolas. Donde tirar recursos para irem à capital? Para resolver o problema, foram criadas escolas isoladas modelo também nas cidades interioranas.

Apesar de, em 1913, o estado de São Paulo contar com 14 escolas isoladas modelo - uma seção para cada sexo - em sete municípios e duas na capital, nos relatórios seguintes os inspetores seguiam denunciando o estado lastimável das escolas isoladas, propondo medidas que atenuassem os problemas.

Informando ao secretário do Interior que o estado das escolas isoladas continuava precário, o diretor geral da Instrução Pública afirmava:

[...] esse mal [a organização do ensino], ao que penso, pode ser remediado, indo o Estado ao encontro do professor, fornecendo-lhe, além do material preciso para sua escola, a casa onde deva a mesma funcionar. Difícil e dispendioso seria fornecer a cada professor uma casa 
para sua escola; mais fácil e proveitoso será fornecer uma casa para diversas escolas.

É assim que, em cada distrito de paz, e para cada três ou quatro escolas, poderia o governo alugar casas onde instalá-las, com as precisas ou possíveis condições pedagógicas. Não se trata de escolas reunidas, segundo o tipo já existente em algumas localidades do interior: cada escola deve funcionar automaticamente sob a regência do seu professor, tendo a casa um zelador, encarregado da sua limpeza e conservação, assim como do arranjo de cada uma das salas (REIS JUNIOR, 1914).

Dentre os maiores obstáculos à organização das escolas isoladas, os inspetores apontavam: a) falta de casa apropriada; b) inferioridade de vencimentos em relação aos dos adjuntos dos grupos escolares; c) residência do professor fora da sede de sua escola; d) facilidade de remoções; e) facilidade em obter licença; f) falta de concurso das famílias; g) deficiência e irregularidade da inspeção municipal; h) ingerência indébita da política na escola; i) falta de prêmio ao esforço profícuo. ${ }^{13}$

Em 1917, João Chrysostomo, ainda diretor geral da Instrução Pública, relatava:

As escolas isoladas continuam a reclamar medidas de rigor para que preencham seu fim. Em regra, prestam muito mau serviço à causa da disseminação do ensino. [...] Penso que duas medidas se impõem para que essas escolas preencham o seu fim: $1^{a}$ ) a fixação do professor na sede de sua escola; $2^{a}$ ) a redução dos programas para as escolas rurais. ${ }^{14}$

No mesmo relatório, o diretor geral propunha algumas ideias para a reforma do ensino; dentre elas, a divisão das escolas isoladas em rurais e urbanas, estas com curso de três anos; aquelas, de dois anos. Nas escolas rurais, deveriam diminuir-se ao mínimo possível as matérias essenciais e adicionar-se noções práticas de agricultura e zootecnia. Nas urbanas, o programa seria o mesmo dos três primeiros anos dos grupos escolares, com exclusão das matérias que, sem prejuízo da cultura geral, pudessem ser dispensadas.

Em 1911, pelo Decreto 2.005 (SÃO PAULO, 1911), o programa de ensino já passara por uma redução. Além disso, o curso passou a ser dividido em seções. Nos grupos escolares o curso durava quatro anos, subdividido em oito séries, cada série

\footnotetext{
${ }^{13}$ Ibid., p. 29.

${ }^{14}$ Id., 1917, p. 10.
} 
correspondendo a um semestre do ano letivo. Esta divisão nas escolas isoladas era problemática, uma vez que os professores, dadas as condições da escola, não conseguiam vencer os programas. Assim, cada série, que no grupo escolar durava um semestre, nas escolas isoladas durava um ano, fazendo dobrar o tempo dos alunos nas escolas. Para resolver tal problema, o curso, com duração de quatro anos, passou a ser dividido em três seções, podendo a $1^{\text {a }}$ seção ser subdividida em duas classes: A e B.

Voltemos à ideia de João Chrysostomo de classificar as escolas isoladas em rurais e urbanas, o que se tornou lei em 1917: "As escolas isoladas do Estado ficam classificadas em: rurais, distritais e urbanas" (Art. $1^{\circ}$ da Lei $n^{\circ} 1.579$, de 19 de dezembro de 1917), (SÃO PAULO, 1917).

Nas escolas rurais, localizadas nas propriedades agrícolas, nos núcleos coloniais e nos centros fabris, o curso duraria dois anos, devendo o programa de ensino ser adaptado às necessidades da zona em que funcionassem. Os vencimentos dos professores dessas escolas seriam iguais aos das escolas distritais. As escolas distritais, situadas em bairros ou sedes de distritos de paz, teriam o curso de três anos e o programa, consequentemente, seria mais desenvolvido que o das escolas rurais. Já nas escolas urbanas, criadas em sede de município, o curso seria de quatro anos e o seu programa abrangeria todo o ensino preliminar.

Já em 1909, Oscar Thompson chamava a atenção para um grave problema:

O problema do ensino, em São Paulo, reside na deficiência de escolas públicas para comportar a população infantil em idade escolar.

Ao governo faltam os recursos pecuniários para aumentar o número de estabelecimentos de ensino, apesar da verba avultada que sob a rubrica instrução pública absorve quantia não pequena da receita do Estado.

Mas o governo não pode ficar impassível, precisa estudar a questão e resolve-la, a fim de que o número de vagas nas escolas seja superior ou, pelo menos, igual ao número de candidatos a matrícula. ${ }^{15}$

Devido à falta de recursos pecuniários, que se arrastou por toda a década de 1910, o governo paulista optou por expandir o número de vagas, não construindo novos

\footnotetext{
${ }^{15}$ Id., 1908-1909, p. 315.
} 
prédios escolares, mas dobrando o turno naqueles já construídos, quer fossem grupos escolares, escolas reunidas ou isoladas. Referente às isoladas, rezava o artigo $1^{\circ}$, da Lei $\mathrm{n}^{\circ}$ 1.710, de 27 de dezembro de 1919, que "todas as escolas isoladas do Estado, com exceção das noturnas, poderão funcionar em dois períodos, sempre que o governo achar conveniente".

Mas foi, conforme Carvalho (2003, p. 227), no "início da década de 1920 que o modelo paulista entrou em crise". Para esta autora, a crise no sistema de ensino foi determinada, além de mutações nos paradigmas de conhecimento, por "motivações políticas, sociais e econômicas que confluíram para o chamado entusiasmo pela educação."

Para Nagle (1974, p. 99), uma das maneiras mais diretas de situar a questão transformações nos setores econômico, político, social e cultural - consistia em afirmar o resultado dessas transformações:

O aparecimento de um inusitado entusiasmo pela escolarização e de marcante otimismo pedagógico; de um lado, existe a crença de que, pela multiplicação das instituições escolares, da disseminação da educação escolar, será possível incorporar grandes camadas da população na senda do progresso nacional, e colocar o Brasil no caminho das grandes nações do mundo; de outro lado, existe a crença de que determinadas formulações doutrinárias sobre a escolarização indicam o caminho para a verdadeira formação do novo homem brasileiro (escolanovismo) (NAGLE, 1974, p. 99-100).

É nesse contexto que Sampaio Dória assume como diretor da Instrução Pública do Estado de São Paulo.

\section{A reforma Sampaio Dória}

Na década de 1920:

O Brasil atravessava uma crise econômica das mais difíceis, a lavoura cafeeira sofrendo os efeitos de uma violenta baixa de preços por causa da superprodução e o povo sofrendo o cambio a 4 pence por mil réis, nível mais baixo já atingido pelo nosso dinheiro até 1930 (BASBAUM, 1986, p. 226). 
A crise socioeconômica difundiu-se na reação violenta causada por vários eventos nacionais, principalmente pela fundação do Partido Comunista Brasileiro, em 1922, e pelos movimentos armados contra o poder central ${ }^{16}$.

Os reflexos da crise se faziam sentir na educação. Em 1920, Sampaio Dória dirigiu um recenseamento escolar, evidenciando que:

das 547.975 crianças, entre 7 e 12 anos (idade escolar) residentes no estado, apenas 175.830 frequentavam escolas públicas e particulares (o que correspondia a $31,6 \%$ ). O restante, isto é, $69,4 \%$ da população escolar, o equivalente a 372.141 crianças, não frequentavam escolas (DÓRIA, 1920. Apud SOUZA, 2009, p. 121).

O analfabetismo grassava não só no estado de São Paulo, mas em todo o País.

Dentro das condições econômicas, políticas e sociais que se impunham e tendo em conta as condições limitadas dos recursos públicos, "que não permitiam dar educação primária a todos, o Estado, segundo Sampaio Dória, deveria atacar o pior, ou seja, o analfabetismo, mesmo que para isso fosse necessário criar um tipo de escola primária aligeirada e simples" (MARCÍLIO, 2005, p. 141). Foi com este espírito que o diretor da Instrução Pública efetuou, em 1920, a reforma regulamentada pela Lei $n^{\circ} 1.750$, de 8 de dezembro do mesmo ano, e pelo Decreto 3.356, de 31 de maio de 1921. Para Nagle (1974, p. 207), esta reforma foi singular no esforço de dar instrução primária a todos, de acordo com a pregação nacionalista da época.

O artigo $1^{\circ}$ do Decreto 3.356 (SÃO Paulo, 1921), estabelecia que a instrução pública compreenderia:

a) o ensino primário, de dois anos, que será ministrado em escolas isoladas, escolas reunidas e grupos escolares;

b) o ensino médio, de dois anos, que poderá ser ministrado em escolas reunidas e grupos escolares;

c) o ensino complementar, de três anos, que será ministrado em escolas complementares;

d) o ensino profissional, que será ministrado em escolas profissionais;

\footnotetext{
${ }^{16} \mathrm{~A}$ Guerra do Contestado (SC/1912-1916) precedeu os movimentos que ocorreram na década de 1920: a comunidade agrícola do beato João Lourenço (1922), no Ceará, destruída a ferro e fogo pela "fúria selvagem dos chamados mantenedores da ordem" (BASBAUM, 1986, p. 223); a luta contra a vacina (1904); a rebelião de João Cândido (1910); a revolta do Forte de Copacabana (1922), que em 1924 teve a adesão da força policial de São Paulo; os movimentos revolucionários de 1922 e 1926; e a Coluna Prestes (1924-1927).
} 
e) o ensino secundário especial, que será ministrado em ginásios e escolas normais;

f) o ensino superior, que será ministrado nas academias e faculdades superiores.

Os quatro anos - subdivididos em oito séries (que compreendiam o curso primário nos grupos escolares e nas escolas isoladas) foram transformados em ensino primário de dois anos e ensino médio, também de dois anos. O primário, ministrado em escolas isoladas, escolas reunidas e grupos escolares, era obrigatório e gratuito a crianças de nove e dez anos de idade (Lei $\mathrm{n}^{\circ} 1.750$, artigo $4^{\circ}$ ), (SÃO PAULO, 1920). Depois de matriculadas as crianças dessas respectivas escolas, as vagas que sobrassem poderiam ser preenchidas, de preferência, por crianças de 11 a 12 anos. Para a matrícula no ensino médio, ministrado em escolas reunidas e grupos escolares, e nos outros cursos, os alunos estavam sujeitos a taxas anuais que os pais ou responsáveis pagariam em duas prestações. Estavam isentos destas taxas os alunos considerados pobres, quais sejam: a) os filhos de indigentes; b) os filhos de operários; c) os filhos dos que vivessem de ordenado mensal até $300 \$ 000$ (Artigo $5^{\circ}$ do Decreto $n^{\circ} 3.356$ ), (SÃO PAULO, 1921).

As escolas isoladas - até então classificadas em urbanas, distritais e rurais com a duração do curso de quatro, três e dois anos respectivamente - passaram a ter um curso com a duração única de dois anos. Quanto à classificação, ficaram as urbanas e as rurais; as "atuais escolas distritais, quando vagarem, serão classificadas em urbanas, ou rurais, segundo a zona onde houverem de funcionar" (Artigo 96, Decreto 3.356), (SÃO PAULO, 1921).

O Artigo 103 prescrevia o método a ser utilizado:

Nas escolas primárias, o método natural do ensino é a intuição, a lição de cousas, o contexto da inteligência com as realidades que se ensinam, mediante a observação e a experimentação, feitas pelos alunos e orientadas pelo professor. São expressamente banidas da escola as tarefas de mera descrição, os processos que apelem exclusivamente para a memória verbal, a substituição das cousas e fatos pelos livros, que se devem apenas usar como auxiliares do ensino (Artigo 96, Decreto 3.356), (SÃO PAULO, 1921).

Conforme Souza (2006, p. 139), “a introdução dos princípios da Escola Nova no final da década de 1910 não significou uma ruptura com o método intuitivo, ao contrário, 
ocorreu em relação de continuidade. Isso é perceptível no pensamento de Sampaio Dória".

Quanto ao ensino nas escolas primárias, o programa compreenderia:

\begin{abstract}
$\checkmark \quad 1^{\circ}$ ano: Linguagem oral; Leitura analítica; Linguagem escrita; Aritmética; Geometria; Geografia e Historia; Ciências Físicas e Naturais; Higiene; Instrução moral e cívica; Desenho; Música; Trabalhos Manuais; Exercícios Ginásticos.

$\checkmark \quad 2^{\circ}$ ano: Leitura; Linguagem oral; Linguagem escrita; Aritmética; Geometria; Geografia; História do Brasil; Ciências Físicas e Naturais; Higiene; Instrução Moral e Cívica; Caligrafia; Música; Trabalhos Manuais; Exercícios Ginásticos.
\end{abstract}

O objetivo de erradicar o analfabetismo fica evidente na Reforma Sampaio Dória. Para Carvalho (2010, p. 96), “nela, o analfabetismo passa a ser a marca da inaptidão dos povos para o progresso. [...] Erradicá-lo é a nova prioridade na hierarquia das providências de política educacional”.

Dentre outras mudanças, a Lei 1.750 de 1920 (SÃO PAULO, 1920), reduziu o ensino primário a dois anos; restringiu a obrigatoriedade e a gratuidade apenas para a faixa etária de nove e dez anos; impôs o desdobramento do turno às escolas isoladas; unificou as escolas isoladas em um tipo único, de dois anos; criou taxas para o ensino, excetuandose o primário, e isentou delas, em todos os graus, os pobres.

É fato que o número de matrículas no ensino público aumentou, como pode ser observado na tabela 1. Mas aumentou no ensino primário, obrigatório e gratuito. $O$ ensino médio, ao qual correspondiam o $3^{\circ}$ e $04^{\circ}$ ano do ensino primário preliminar, diminuiu, uma vez que se tornara facultativo e por sua frequência se cobrava uma taxa anual. 
Tabela 1: Número de Matrículas no Ensino Público após a reforma de 1920

\begin{tabular}{|c|c|c|c|}
\hline & Primário & Médio & Total \\
\hline 1921 & 155.928 & 28.385 & 184.323 \\
\hline 1922 & 156.157 & 25.991 & 182.148 \\
\hline 1923 & 173.096 & 14.598 & 187.694 \\
\hline
\end{tabular}

Fonte: Anuário do Ensino de 1922, p. 369 e 370.

Em 1921 ainda foram matriculadas crianças de sete e oito anos. A partir de 1922, não foram mais aceitas tais matrículas. Três foram os meios práticos de execução da obrigatoriedade colocados em prática pela Diretoria da Instrução Pública, quer nos grupos escolares, escolas reunidas ou isoladas:

Para ser efetuada matrícula de todas as crianças de 9 e 10 anos existentes no núcleo em que funcionam os estabelecimentos de ensino além do Recenseamento Escolar [...] a diretoria de ensino instituiu o policiamento exercido pelos próprios alunos que se transformam em auxiliares solertes na campanha alfabetizante. Todos os dias, nos primeiros minutos de aula, os professores indagam dos alunos se conhecem alguma criança de 9 ou 10 anos que não frequentam escola. A princípio parece desnecessário que a indagação seja feita diariamente, porém, num estado como o de São Paulo em que a corrente imigratória é contínua, em que as cidades recebem diariamente novos moradores, a vigilância das crianças, espalhadas em todas as direções do núcleo, é preciosa e eficaz.

Os alunos que promovem a matrícula de novas crianças recebem o título de patriotas e são inscritos no quadro-negro. Os que indicam dez ou mais alunos novos, são considerados auxiliares de alfabetização. Aos refratários aplicam, as autoridades escolares, as sanções da lei (KUHLMANN, 1922).

Contudo, os índices de analfabetismo continuavam altos: em 1920, a escola não atingia mais que $28 \%$ da população escolarizável. Uma das razões, afirma Marcilio (2005, p. 93), estava no fato de que as taxas de crescimento demográfico apresentavam barreiras à universalização do ensino: "Por mais que se abrissem novas escolas, o crescimento da população era mais rápido e vencia sempre a corrida." Além disso, havia, na expressão de Antunha (1976, p. 54), um conflito diante da opção entre o desenvolvimento quantitativo e qualitativo do ensino. Este conflito foi encontrado no cerne da Reforma de 1920. 
Para Nagle (1974, p. 207), desde 1918 o problema da instrução pública do Estado de São Paulo já se encontrava proposto nos seguintes termos:

[...] encontrar uma fórmula para resolver o problema do analfabetismo, nas condições atuais, isto é, considerando, de um lado, a existência de 380 mil crianças de 7 a 12 anos, com uma matrícula geral de 232 mil; de outro lado, a situação orçamentária do Estado, que não suportava maiores gastos no setor. Essa mesma situação se agravará em 1920, como se nota pelos termos da Mensagem que, nesse ano, o Presidente do Estado dirigiu ao Congresso Legislativo: com a nossa organização atual, só menos da metade da população escolar pode receber instrução primária.

Mas a Reforma Sampaio Dória sofreu duras críticas, principalmente por ter reduzido o ensino obrigatório e gratuito para dois anos. Assim, o Decreto $n^{\circ} 3.858$, de 11 de junho de 1925 (SÃO PAULO, 1925), regulamentou uma nova reforma, restabelecendo o curso primário de quatro anos nos grupos escolares e de três anos nas escolas reunidas e isoladas. O ensino primário voltou a ser obrigatório e gratuito para as crianças de ambos os sexos de sete a doze anos de idade (artigo $2^{\circ}$ ) e ministrado em escolas isoladas, escolas reunidas, grupos escolares, escolas e cursos noturnos, escolas-modelo e escolas isoladas modelo (Artigo 19). As escolas isoladas, criadas pelo Congresso por proposta do governo, seriam urbanas ou rurais (Artigo 21).

\section{A quem destinavam as escolas isoladas?}

Em 1909, Oscar Thompson, então diretor geral da Instrução Pública, já dizia:

Tudo progrediu no departamento do ensino: apenas a escola isolada permaneceu quase a mesma que era há 50 anos. Estacionou no mesmo lugar, com todos os seus erros e defeitos de origem. Com efeito, quando se observam as escolas complementares e o funcionamento lógico dos grupos escolares - o tipo mais perfeito de organização escolar - e se entra por acaso em uma escola isolada, o coração do educador fica profundamente consternado e ao seu espírito acode insensivelmente a crítica severa contra os responsáveis pela sua permanência. ${ }^{17}$

Duas reformas de peso definiram os rumos da instrução pública no primeiro período republicano em São Paulo. Erguer os templos do saber, nos quais funcionariam

\footnotetext{
${ }^{17}$ In: Anuário do Ensino do Estado de São Paulo. 1908-1909, p. 82.
} 
escolas graduadas, com novos métodos, abundância de material, professores bempreparados revelava o progresso inconteste do "ensino público comparado à situação das escolas de primeiras letras predominantes no regime monárquico" (SOUZA, 2009, p. 30). No entanto, as circunstâncias econômicas e políticas fizeram com que a instituição modelar e a escola de primeiras letras, agora convertidas em escolas isoladas, coexistissem, adentrando o segundo período republicano.

Assim, para os grandes centros urbanos, instalaram-se grupos escolares; para os menores centros e bairros populosos, escolas reunidas. Contudo, estas escolas não atendiam aos bairros afastados, periféricos, às vilas, nem às áreas rurais. Para alcançar a universalização pretendida, a instrução deveria chegar também às crianças que habitavam esses locais. Coube, então, às escolas isoladas a função de atender a essas crianças que, nas palavras dos professores, eram muito pobres, paupérrimas, crianças que precisavam ajudar os pais na lida diária. Para Oscar Thompson, diretor geral da Instrução Pública em 1910:

As escolas isoladas devem ter entre nós, como tem em toda parte, a missão bem simples e modesta. Educar em pouco tempo crianças cujo serviço é muito cedo aproveitado pelos pais é, em regra, o papel de tais escolas. Devem elas, por isso, dar uma instrução que corresponda às necessidades futuras de seus alunos. ${ }^{18}$

Conforme Cunha (1978, p. 114), tem-se que:

[...] a generalização da educação elementar fez-se, entretanto, sob a marca da separação das classes sociais. As escolas elementares destinadas aos filhos dos trabalhadores eram de qualidade muito baixa, de modo que a educação por eles recebida era incomparavelmente inferior à dos filhos das classes dominantes e das camadas médias.

As palavras supracitadas do diretor geral Oscar Thompson refletem bem a marca apontada por Cunha.

Também a investigação realizada por Santos (2011) aponta nessa direção. Explicitando a formação escolar da elite limeirense, a autora afirma que essas famílias

[...] escolhiam outros estabelecimentos que não o Grupo Escolar. Apenas dois dos 14 descendentes da família Levy cursaram o Grupo Escolar de

\footnotetext{
${ }^{18}$ Id.. 1909-1910, p. 25.
} 
Limeira - todos os outros foram para outras cidades, Estados ou país, e os que ficaram na cidade estudaram em instituição particular. [...] Se representantes da história local não escolheram o Grupo Escolar para instruir seus filhos é porque esse estabelecimento de ensino não atendia às expectativas dessa classe.

Conforme Basbaum (1986, p. 128), no período da Primeira República, São Paulo se destacava no conjunto do País não apenas como produtor, mas também como consumidor. Para este autor, "o crescimento das cidades criou um mercado interno bastante animador, estimulando a indústria, desenvolvendo o comércio criando uma vida nova e mais agitada para as cidades." Essas condições, continua o historiador, propiciaram a formação das

[...] primeiras grandes fortunas não originadas diretamente do café. [...] Nascia, pelos casamentos e pela fusão de interesses econômicos uma nova burguesia, uma nova alta sociedade, fundada na riqueza proveniente do comércio e da indústria (BASBAUM, 1986, p. 168).

Essa parcela da população urbana compunha, junto com a dos fazendeiros, a elite paulista cujos filhos estudavam em escolas particulares locais ou em outras cidades e no exterior. Além da elite, Basbaum (1986, p. 171) distingue, na população urbana, a formação das classes médias:

Designamos como classes médias urbanas todas aquelas categorias sociais que se colocam entre o proletariado e a grande burguesia urbana. Nelas incluímos não apenas os pequenos fabricantes, donos de pequenas oficinas, artesãos e pequenos comerciantes, como ainda o funcionalismo público, as chamadas 'profissões liberais' e intelectuais e ainda os militares, não tanto pelas suas condições de vida (referimo-nos a todas as categorias citadas), diferentes entre si, mas pela sua ideologia, pelas suas concepções de vida.

Ainda nas palavras de Basbaum (1986, p. 172):

[...] é dentro dessa camada social [...] de pequenos lojistas, pequenos fabricantes e mestres-artesãos, alfaiates, marceneiros, sapateiros, etc., que se verifica outro dos mais importantes fenômenos sociais desse período, a proletarização das classes médias. Os mais fracos, empobrecidos, são forçados a abandonar os seus pequenos negócios e a transformar-se em funcionários públicos, em empregados de lojas mais ricas ou em operários de fábricas mais poderosas. 
Essas camadas proletarizadas compunham, junto com os operários industriais, o proletariado, setor popular de menor poder aquisitivo que, segundo Basbaum (1986, p. 177), no primeiro período republicano brasileiro, não constituía, ainda, uma classe homogênea: "Sem preparo técnico, analfabetos em sua grande maioria, sujeitavam-se aos baixos salários e a condições de trabalho as mais terríveis" (BASBAUM, 1986, p. 178). Também compunham essa camada ex-escravos, retirantes, agregados ou moradores fugidos do campo. Mas à medida que aumentava a concentração urbana e "à medida que as necessidades os iam lançando em lutas reivindicatórias, iam os operários constituindo uma classe social definida com caracteres e reivindicações próprias" (BASBAUM, 1986, p. 177).

Na população rural, o autor em questão destaca duas classes: de um lado, a classe de proprietários de terra, os fazendeiros, e, de outro, três subclasses ou "três grandes categorias: a dos pequenos proprietários, a dos que trabalham em terra alheia mediante pagamento em dinheiro ou espécie ao dono da terra [arrendatários e colonos], e o assalariado" [trabalhadores rurais] (BASBAUM, 1986, p. 150).

Para Nagle (1974, p. 26), no primeiro período republicano, as camadas médias brasileiras estavam em intenso processo de formação:

O desenvolvimento do modo capitalista de produção e de vida, durante a república Velha, ocasionou o aceleramento da divisão social do trabalho e exigiu nível cada vez mais crescente de especialização de funções, de que resultaram o aparecimento de novas camadas sociais e a diferenciação das antigas classes dominantes; [...] na década dos vinte, os sinais de aparecimento de novo modelo se apresentam de maneira mais manifesta pela presença de desarmonia de valores, interesses e expectativas dos diversos agrupamentos.

Essa incursão pela formação das classes sociais no primeiro período republicano foi necessária para tentarmos identificar quem eram os pais das crianças que frequentavam as escolas isoladas, pois:

À medida que os grupos escolares eram criados em zonas urbanas caracterizando um tipo de escola de melhor qualidade [...] consolida-se um sistema escolar excludente de várias maneiras, entre elas, privilegiando determinados setores sociais, principalmente camadas médias e populares relacionadas às atividades urbano-industriais e 
discriminando setores populares de menor poder aquisitivo vinculados ou não às atividades rurais. (SOUZA, 2009, p. 85)

As escolas isoladas atendiam aos "setores populares de menor poder aquisitivo vinculados ou não às atividades rurais"? Dos mais de 60 livros de matrículas consultados destaquei oito, dos quais transcrevo, na tabela 2, os dados referentes à profissão dos pais dos alunos das escolas isoladas paulistas. Por esta tabela, procurei identificar qual era o público atendido por essas escolas.

Antes da tabela 2, apresento o quadro 1, com a função de identificar os dados referentes às oito escolas cujos dados compõem a tabela 2. Por exemplo, os dados da coluna 1 estão no Arquivo Público do Estado de São Paulo, identificados pela Ordem 04031 e pertencem à $1^{\text {a }}$ Escola do sexo feminino de Santa Cruz da Estrella, no ano de 1905, quando a escola tinha 58 alunas matriculadas. Em todas as escolas, a idade variava entre seis e catorze anos.

Quadro 1: Identificação das oito escolas selecionadas

\begin{tabular}{|c|c|c|c|c|}
\hline Coluna & Ordem & Alunos & Ano & Escola \\
\hline 01 & 04031 & 58 & 1905 & $1^{\text {a }}$ Escola do sexo feminino de Santa Cruz da Estrella \\
\hline 02 & 04193 & 62 & 1913 & Escola do sexo feminino da Lapa \\
\hline 03 & 04163 & 40 & 1912 & Escola do sexo feminino de Bella Cintra \\
\hline 04 & 04167 & 47 & 1913 & Escola do sexo feminino do Bairro da Mooca \\
\hline 05 & 04031 & 40 & 1907 & $4^{\text {a }}$ Escola do sexo feminino de Santa Rita do Passa Quatro \\
\hline 06 & 3910 & 56 & 1908 & $2^{\text {a }}$ Escola do sexo masculino de São Bernardo \\
\hline 07 & 3910 & 42 & 1911 & $2^{\text {a }}$ Escola do sexo masculino de São Bernardo \\
\hline 08 & 3926 & 41 & 1907 & Escola Pública do sexo masculino da cidade de São Vicente \\
\hline
\end{tabular}

Fonte: Arquivo Público do Estado de São Paulo, Livros de Matrícula: Ordem 04031; 04193; 04163; 04167; 3910; e 3926.

Selecionei as oito escolas cujos livros de matrículas estavam mais completos. Quanto à profissão dos pais, a leitura dos demais livros revelou dados muito parecidos, 
não aparecendo camadas sociais diferentes, conforme se vê nas profissões apresentadas na tabela 2:

Tabela 2: Profissão dos pais de alunos de oito escolas isoladas

\begin{tabular}{|c|c|c|c|c|c|c|c|c|}
\hline & 1 & 2 & 3 & 4 & 5 & 6 & 7 & 8 \\
\hline Operário & $x$ & 43 & 12 & 08 & $x$ & $x$ & 11 & $x$ \\
\hline Lavrador & 29 & 06 & 01 & $x$ & 01 & 13 & 02 & 06 \\
\hline Serrador & 03 & $x$ & $x$ & $x$ & $x$ & $x$ & $x$ & $x$ \\
\hline Sapateiro & 01 & $x$ & 02 & 01 & $\mathrm{x}$ & $\mathrm{x}$ & $\mathrm{x}$ & $\mathrm{x}$ \\
\hline Negociante & 22 & $x$ & 04 & 04 & 03 & 03 & 04 & 03 \\
\hline Comerciante & 01 & $x$ & $\mathrm{x}$ & $x$ & $x$ & $x$ & $x$ & $x$ \\
\hline Empregado & $x$ & 06 & 06 & 08 & $x$ & $x$ & $x$ & 01 \\
\hline Criada & $x$ & $x$ & $\mathrm{x}$ & $x$ & 01 & $x$ & $x$ & 01 \\
\hline Médico & $x$ & $x$ & $x$ & $x$ & $x$ & $x$ & $x$ & 01 \\
\hline Roceiro & $x$ & $x$ & $x$ & $x$ & 06 & $x$ & $x$ & 01 \\
\hline Pedreiro & $x$ & $x$ & 01 & $x$ & 03 & $x$ & $x$ & 02 \\
\hline Lavadeira & $x$ & $x$ & 01 & $x$ & $x$ & $x$ & $x$ & 01 \\
\hline Banqueiro & $x$ & $x$ & $x$ & $x$ & $x$ & $x$ & $x$ & 02 \\
\hline Guarda-Livros & $x$ & $x$ & $x$ & $x$ & $x$ & $x$ & $x$ & 01 \\
\hline Fiscal da Estr. Ferro & $x$ & $x$ & $x$ & $x$ & $x$ & $\mathrm{x}$ & $x$ & 01 \\
\hline Alferes & $x$ & $x$ & $\mathrm{x}$ & $x$ & $x$ & $x$ & $x$ & 01 \\
\hline Professor & $x$ & $x$ & $x$ & $x$ & $x$ & $x$ & $x$ & 01 \\
\hline Jardineiro & $x$ & $x$ & 01 & $x$ & $x$ & $x$ & $x$ & 01 \\
\hline Pescador & $x$ & $x$ & $x$ & $x$ & $x$ & $x$ & $x$ & 01 \\
\hline Carniceiro & $\mathrm{x}$ & $x$ & $x$ & $x$ & $x$ & $x$ & $x$ & 01 \\
\hline Açougueiro & $x$ & $x$ & $\mathrm{x}$ & $x$ & $x$ & $x$ & $x$ & 01 \\
\hline Gerente & $x$ & $x$ & $x$ & $x$ & $x$ & $x$ & $x$ & 01 \\
\hline Marmorista & $x$ & $x$ & 02 & $x$ & $x$ & $x$ & $x$ & $x$ \\
\hline Alfaiate & $\mathrm{x}$ & $x$ & 05 & 01 & 02 & $x$ & $x$ & $x$ \\
\hline Marceneiro & $x$ & $x$ & 01 & 03 & $\mathrm{x}$ & $x$ & $x$ & $x$ \\
\hline Chineleiro & $x$ & $\mathrm{x}$ & 01 & $\mathrm{x}$ & $\mathrm{x}$ & $\mathrm{x}$ & $\mathrm{x}$ & $\mathrm{x}$ \\
\hline
\end{tabular}




\begin{tabular}{|c|c|c|c|c|c|c|c|c|}
\hline & 1 & 2 & 3 & 4 & 5 & 6 & 7 & 8 \\
\hline Fruteiro & $x$ & $x$ & 01 & $x$ & $x$ & $x$ & $x$ & $\mathrm{x}$ \\
\hline Ferreiro & $\mathrm{x}$ & $x$ & 01 & $x$ & $\mathrm{x}$ & $\mathrm{x}$ & $\mathrm{x}$ & $\mathrm{x}$ \\
\hline Funcionário & $x$ & $x$ & $x$ & 01 & $x$ & 02 & $x$ & $\mathrm{x}$ \\
\hline Carroceiro & $x$ & $\mathrm{x}$ & $x$ & 03 & 05 & 03 & $x$ & $\mathrm{x}$ \\
\hline Cocheiro & $x$ & $x$ & $x$ & 02 & $x$ & 02 & $x$ & $\mathrm{x}$ \\
\hline Carpinteiro & $x$ & $x$ & $x$ & 03 & 04 & $x$ & $x$ & $\mathrm{x}$ \\
\hline Funileiro & $x$ & $x$ & $x$ & 02 & $x$ & $x$ & $x$ & $\mathrm{x}$ \\
\hline Pintor & $x$ & $\mathrm{x}$ & $x$ & 01 & $x$ & $\mathrm{x}$ & $\mathrm{x}$ & $\mathrm{x}$ \\
\hline Vaqueiro & $x$ & $\mathrm{x}$ & $x$ & 01 & $x$ & $x$ & $\mathrm{x}$ & $\mathrm{x}$ \\
\hline Mecânico & $x$ & $\mathrm{x}$ & $x$ & 04 & $x$ & 03 & $x$ & $\mathrm{x}$ \\
\hline Soldado & $x$ & $x$ & $x$ & $\mathrm{x}$ & 01 & $x$ & $x$ & $\mathrm{x}$ \\
\hline Contador & $x$ & $\mathrm{x}$ & $x$ & $x$ & 01 & $\mathrm{x}$ & $\mathrm{x}$ & $\mathrm{x}$ \\
\hline Fogueteiro & $x$ & $x$ & $x$ & $x$ & 01 & $x$ & $x$ & $\mathrm{x}$ \\
\hline Relojoeiro & $x$ & $x$ & $x$ & $x$ & 04 & $x$ & $x$ & $\mathrm{x}$ \\
\hline Ferreiro & $x$ & $\mathrm{x}$ & $x$ & $x$ & 02 & $\mathrm{x}$ & $\mathrm{x}$ & $\mathrm{x}$ \\
\hline Cervejeiro & $x$ & $x$ & $x$ & $x$ & 02 & $x$ & $x$ & $\mathrm{x}$ \\
\hline Vendeira & $x$ & $x$ & $x$ & $x$ & 01 & $x$ & $x$ & $\mathrm{x}$ \\
\hline Padeiro & $x$ & $x$ & $x$ & $x$ & 01 & $x$ & $x$ & $\mathrm{x}$ \\
\hline Selheiro (sic) & $x$ & $x$ & $x$ & $x$ & 01 & 02 & $\mathrm{x}$ & $\mathrm{x}$ \\
\hline Artista & $x$ & $\mathrm{x}$ & $x$ & $x$ & 01 & $x$ & $x$ & $\mathrm{x}$ \\
\hline Colono & $x$ & $x$ & $x$ & $x$ & $x$ & 09 & $x$ & $\mathrm{x}$ \\
\hline Barbeiro & $x$ & $x$ & $x$ & $x$ & $x$ & 02 & $x$ & $\mathrm{x}$ \\
\hline Agricultor & $x$ & $\mathrm{x}$ & $x$ & $x$ & $x$ & 02 & $x$ & $\mathrm{x}$ \\
\hline Militar & $x$ & $x$ & $x$ & $x$ & $x$ & $x$ & 01 & $\mathrm{x}$ \\
\hline Carvoeiro & $x$ & $x$ & $x$ & $x$ & $x$ & $x$ & 01 & $\mathrm{x}$ \\
\hline Sacristão & $x$ & $x$ & $x$ & $x$ & $x$ & $x$ & 01 & $\mathrm{x}$ \\
\hline Boiadeiro & $x$ & $x$ & $x$ & $x$ & $x$ & $x$ & 01 & $\mathrm{x}$ \\
\hline Não citaram & 02 & 07 & $x$ & 04 & $x$ & 04 & $x$ & $\mathrm{x}$ \\
\hline
\end{tabular}

Fonte: Arquivo Público do Estado de São Paulo, Livros de Matrícula: Ordem 04031; 04193; 04163; 04167; 3910; e 3926. 
Excluindo o caso da escola pública do sexo masculino da cidade de São Vicente (coluna 8, Quadro 1), na qual estão matriculados os quatro filhos do médico, os dois filhos dos dois banqueiros, 1 filho do guarda-livro, 1 do fiscal geral da estrada de ferro, 1 do alferes e três filhos do gerente, todas as outras profissões se relacionam com a análise feita por Basbaum (1986, p. 178) sobre a formação do proletariado paulista, ou seja, da classe menos favorecida. Em 1921, ao reduzir a gratuidade às duas primeiras séries do ensino primário e, consequentemente, a cobrança de taxas para os outros níveis de ensino, o Decreto $\mathrm{n}^{\circ} 3.356$, no artigo $5^{\circ}$, isentava de tais taxas os pobres: “Consideram-se pobres para obterem a isenção de taxa: a) os filhos de indigentes; b) os filhos de operários; c) os filhos dos que vivem de ordenado mensal até 300\$000."

Esclarecendo a questão das matrículas - dos filhos do médico, dos banqueiros, do guarda-livro, do fiscal geral da estrada de ferro, do alferes e do gerente - na escola pública do sexo masculino da cidade de São Vicente, cabe dizer que o primeiro grupo escolar daquela cidade "foi instalado pelo governo do estado em agosto de 1913" (http://www.crmariocovas.sp.gov.br/pdf/neh/1911-1915/1913_sao_vicente.pdf).

Depreende-se que os filhos do alferes, médico etc. foram matriculados na escola isolada porque não havia grupo escolar no pequeno município. Quando este foi instalado na cidade, os nomes dos filhos da camada média desaparecem do livro de matrícula da escola isolada.

Concordando com Cunha (1978, p. 114), que afirma que a generalização da educação elementar se fez sob a marca da separação das classes sociais, posso concluir que, no período da Primeira República foi conveniente manter as escolas isoladas para atender às camadas populares suburbanas e/ou rurais, economicamente carentes. Nos grandes centros urbanos, os grupos escolares atendiam aos filhos dos trabalhadores mais especializados. No entanto, nas pequenas cidades, onde todas as escolas isoladas urbanas foram agrupadas, os grupos escolares atendiam aos filhos dos residentes, temporariamente sem separação de classes. 
O teor do documento seguinte movimenta-se nessa direção. No ofício ${ }^{19}$ datado de 14 de março de 1911, do Almoxarifado da Secretaria do Interior ao Secretário do Interior, o sr. Francisco Botelho, responsável pelo setor, expõe sua opinião a respeito do pedido de blocos de caligrafia. Para ele "devem ser adquiridos pelos alunos que o possam, fornecendo o grupo, pela verba de expediente, para os que forem reconhecidamente pobres." Diz ele que, se o Estado tiver de fornecer até blocos de caligrafia para os grupos já instalados, a verba calculada para o material escolar não daria até abril. O aluno ou os pais que não são carentes precisariam concorrer crescentemente ao menos com cadernos, lápis, pena, afirma o responsável pelo almoxarifado.

Assim para a elite (escolas particulares nacionais ou estrangeiras); para a classe média, os grupos escolares; para a classe menos favorecida, as escolas isoladas.

\section{Considerações finais}

[...] debaixo dos pés de cada geração que passa na terra dormem as cinzas de muitas gerações que a precederam. (HERCULANO, 1965, p. 9)

Conforme Saviani (2007, p. 16), o movimento global do conhecimento se constitui por um momento inicial no qual o objeto é confusamente captado, aparecendo como um problema que precisa ser resolvido. Partindo do problema a ser resolvido, chega-se, por meio de análise, aos conceitos, às abstrações, às determinações mais simples. Atingido este ponto, faz-se necessário percorrer o caminho inverso, chegando, pela via da síntese, de novo ao objeto. Fase difícil! Mas é o que tentarei: percorrer o caminho inverso.

Com a independência, tornou-se necessário elevar o Brasil ao nível das nações civilizadas, para o que era preciso que o povo fosse civilizado, disciplinado, moralizado. Para tanto, o Império brasileiro deveria promover a universalização do ensino elementar. Mas, como ampliar o acesso da população à instrução pública sem riscos para a ordem constituída? Naquele momento histórico, a solução que se apresentava era o método de

\footnotetext{
${ }^{19}$ Neste ofício, o responsável pelo almoxarifado está se referindo a um pedido feito pelo diretor do Grupo Escolar do Carmo. AESP. Ordem 6.360.
} 
Lancaster. Sua adoção na instrução popular paulista destinava-se à população pobre, ou às classes inferiores e objetivava uma formação básica - leitura, escrita e as operações elementares da aritmética - enfatizando a moralidade e a disciplinarização, como meios de promover a ordem social e construir a nova nação dentro dos moldes das nações civilizadas. Mas essa necessidade não foi suprida e o Império deixou à República uma vasta tarefa a cumprir no campo da instrução pública.

Assim, nos primórdios da República, uma grande campanha foi encetada promovendo as reformas que buscariam a universalização da instrução pública, uma necessidade social e política. Social, porque ainda era preciso civilizar, disciplinar, moralizar, higienizar o povo. Acrescento que esses eram os princípios da racionalidade científica e da divisão técnica do trabalho. Conforme Souza (1998, p. 92), era nas cidades que morava o perigo das multidões - a influência malsã dos pobres, dos vagabundos, de um povo com tendências à degeneração. As cidades constituíam o espaço onde deveriam ser tomadas medidas urgentes de disciplinarização e de regeneração social e a escola foi uma das instituições responsabilizadas por essa missão. Política, porque, para ser democrático, o governo republicano precisava contar com a participação do povo, ainda que fosse somente no período eleitoral. Para tanto, a alfabetização se tornou uma exigência.

Mas era preciso romper com o modelo imperial que não havia surtido quase nenhum efeito, legando à República um grande contingente de analfabetos. Um novo sistema de escolas públicas precisava ser implantado, agora buscando atender ao ideário republicano da modernização e do progresso do novo país e promovendo a ordem, a moralização, a higienização, o fortalecimento da economia, principalmente através do combate ao analfabetismo do povo brasileiro. É nesse contexto que surgem os grupos escolares, um novo modelo de escola primária, portando uma nova organização administrativa e pedagógica, concebida nos princípios da racionalidade científica e na divisão do trabalho.

Mas o grupo escolar não foi o único modelo de instituição escolar do novo sistema que tinha nas escolas elementares do Período Imperial a base para a criação: a união dessas escolas gerou os grupos escolares; a reunião, as escolas reunidas; e o isolamento, 
as escolas isoladas. A união, a reunião ou o isolamento dependiam tanto da localização das escolas e do número de alunos matriculáveis quanto do público-alvo.

A formação dos grupos escolares pautou-se na união de escolas elementares, ou de primeiras letras, num mesmo prédio, construído especialmente para abrigar uma instituição escolar. Compunha-se de várias salas, cada uma correspondendo a uma classe supostamente homogênea, cada classe sob a regência de um professor. Os grupos escolares, ao destinar-se a um grande número de crianças, tornavam-se o modelo mais adequado à escolarização em massa e às necessidades de universalizar a educação popular, atendendo à classe média.

Da reunião das escolas de primeiras letras nasceu outro modelo: as escolas reunidas. Ajuntaram-se em um mesmo prédio várias escolas isoladas, mantendo, no entanto, suas características. As salas eram compostas por alunos de diferentes níveis de adiantamento, regidas por um só professor, que tinha que lidar com a heterogeneidade. Estes estabelecimentos eram instalados em pequenas cidades, ou bairros populosos, que, pelo número de alunos matriculáveis, não comportavam um grupo escolar. Constituíram um modelo transitório, que desapareceu com o passar do tempo.

A pretendida universalização do ensino só seria possível se a instrução alcançasse também o interior do estado, as vilas, os subúrbios e a zona rural. Para este fim, as escolas elementares do Período Imperial foram ajustadas e denominadas escolas isoladas. Assim como seus antecedentes imperiais, as escolas isoladas paulistas foram adotadas para atender à população pobre, residente nos bairros periféricos, nas vilas e áreas rurais. Ao garantir a reprodução social e cultural, assumiram a função reprodutivista, descrita por Perez Gómez (1998). Embora inicialmente devessem cumprir o mesmo conteúdo programático que os grupos escolares, nunca ultrapassaram os conteúdos básicos, assumindo, pedagogicamente, a função de dar aos seus alunos uma formação básica - leitura, escrita e aritmética - e algumas noções elementares de Geografia; Cosmografia; Ciências Físicas, Químicas e Naturais, e Educação Moral e Cívica, enfatizando a moralidade, a disciplinarização, a higienização e a ordem. Como escreve Oscar Thompson, a instrução deveria corresponder às necessidades futuras de seus alunos. 
Enquanto os grupos escolares redefiniram muitos aspectos das escolas de primeiras letras dando-lhes uma dimensão racional, as escolas isoladas mantiveram os aspectos das que lhes antecederam. Quando foram criadas as escolas isoladas modelo, a organização didática das escolas isoladas não se alterou significativamente. Isto porque as escolas isoladas modelo, embora mantivessem na mesma sala alunos de diferentes graus de adiantamento e um só professor, dispunham de um professor adjunto, de espaço adequado, de material e contavam com a assistência do diretor da escola normal à qual estavam anexadas. Disse um professor: "Ela não podia servir de modelo porque as condições físicas e pedagógicas eram ainda muito diferentes das nossas." Embora tenham incorporado muito da organização administrativa e pedagógica dos grupos escolares, as escolas isoladas estavam muito mais próximas das escolas de primeiras letras da época anterior. Conforme Reis Filho (1995, p. 203), os grupos escolares eram o “mais eficiente instrumento para a construção de um Estado republicano democrático", pois mantinham uma organização administrativa e pedagógica pautada na divisão do trabalho e no controle racional do tempo e do programa de ensino. Nas escolas isoladas, porém, o trabalho se manteve com reduzida divisão do trabalho, ou seja, um só mestre ensinava todas as disciplinas a todos os alunos, independente do grau de adiantamento. Alguns fatores contribuíram para essa permanência, quais sejam: a falta de recursos pecuniários, o crescimento demográfico galopante e a grande extensão territorial do estado. Os grupos escolares, instituições dispendiosas, não alcançavam todo o território paulista, pois a população crescia velozmente e demandava cada vez mais escolas. Além disso, os recursos financeiros destinados à instrução não comportavam a demanda. Assim, a solução foi manter as escolas isoladas para atender às classes populares suburbanas e/ou rurais, economicamente carentes.

Dizia Marx (1982, p. 203) que "os homens fazem sua própria história, mas não a fazem como querem; não a fazem sob circunstâncias de sua escolha e, sim, sob aquelas com que se defrontam diretamente, ligadas e transmitidas pelo passado". Tenho claro que mudanças ocorreram, dadas as transformações pelas quais passaram os meios com os quais os homens produzem e reproduzem a vida. Contudo, a história das escolas 
isoladas, no primeiro período republicano, é marcada por aspectos da moderna escola burguesa, especialmente de suas antecessoras, as escolas de primeiras letras.

À primeira vista, as escolas isoladas podem parecer um modelo desajustado, principalmente se as considerarmos em relação aos grupos escolares, o modelo mais desenvolvido. No entanto, no caso da instalação dos grupos escolares, não se pode deixar de dizer que a quantidade de escolas não atendeu à demanda crescente por educação. Os grupos escolares não chegavam às zonas periféricas e rurais.

Para os professores do período inicial da República, as escolas isoladas estavam desorganizadas; para Rossi (2008) tratava-se de um modelo desajustado; para o professor Salomão Hage, "não há nada de desajustado ou desorganizado. Há uma forma precária de se expressar, de se materializar, nas condições existenciais desses territórios marcados pela precarização das condições materiais de sua existência." É sob esse aspecto que é possível entender a permanência das escolas isoladas, uma rede escolar menos eficaz, precária, mantidas para atender às regiões menos desenvolvidas. A demanda que altera o formato da escola em cada região está intimamente relacionada ao processo de desenvolvimento econômico: às regiões menos desenvolvidas e mais pobres, um formato de escola mais simples e mais barato.

Concordando com o professor Salomão, acrescento que as escolas isoladas não estavam desajustadas; tratava-se de um modelo ajustadíssimo:

$\checkmark \quad$ à valorização da cidade em detrimento da zona rural, pois, os grupos escolares foram criados para atender aos centros urbanos;

$\checkmark \quad$ à explosão demográfica, que tomou conta de São Paulo nos primórdios da República;

$\checkmark \quad$ e às localidades onde nem o desenvolvimento econômico, nem o número de crianças matriculáveis comportavam um grupo escolar.

Na Primeira República, as escolas isoladas foram, nas palavras do professor Sérgio Castanho (Palestra em 26/02/2013 na UNICAMP), não só multisseriadas, mas também “multimetodizadas", ou seja, possuíam uma multiplicidade de métodos; 
“multissediadas", pois funcionavam em diversos tipos de prédios, desde salas minúsculas até locais que haviam sido utilizados para açougue, galinheiro; “multiprovidas”, podendo ser regidas tanto por professores leigos, por interinos - habilitados por concurso perante o inspetor de distrito - quanto por professores habilitados pelos regimes anteriores a 1892 e, ainda, por normalistas recém-formados.

Para Souza (2009, p. 66), "o grupo escolar e a escola isolada se constituíram os modelos predominantes de escola primária no Estado de São Paulo até os anos de 1970". Sobre os grupos escolares muito se tem produzido, mas sobre as escolas isoladas e também sobre suas sucessoras, as escolas multisseriadas, muito há para ser inquirido, para ser descoberto. Meu primeiro intuito foi investigar as escolas multisseriadas até os dias atuais; cheguei, porém, às suas antecessoras, as da Primeira República. Muito ainda há por fazer. Fica o campo aberto para outras tantas pesquisas, pois, como afirma Saviani (2007, p. 24), necessitamos conhecer a história das instituições escolares brasileiras.

\section{Referências}

ANTUNHA, Heládio César Gonçalves. A Instrução Pública no Estado de São Paulo: a Reforma de 1920. São Paulo: FEUSP, 1976.

ANNUÁRIO do Ensino do Estado de São Paulo (de 1907-1908; 1908-1909; 1909-1910; 19101911; 1914; 1917; 1922). Publicado e organizado pela Inspectoria Geral do Ensino. São Paulo: Typografia Augusto Siqueira Disponíveis em:

<http://www.arquivoestado.sp.gov.br/educacao/anuario.php> Acesso em:

BASBAUM, Leôncio. História sincera da república: de 1889 a 1930. v. 2. 5. ed. São Paulo: Alfa-Omega. 1986,

CARVALHO, Marta Maria Chagas. Reformas da instrução pública. In: LOPES, Eliane Marta Teixeira; FARIA FILHO, Luciano Mendes; VEIGA, Cyntia Greive (Orgs.). 500 anos de educação no Brasil. 3. ed. Belo Horizonte: Autêntica. 2003.

CARVALHO, Marta Maria Chagas._Sampaio Dória. Recife: Fundação Joaquim Nabuco, Editora Massangana. 2010. Coleção Educadores. 
CUNHA, Luiz Antônio. Educação e desenvolvimento social no Brasil. 3. ed. Rio de Janeiro: Francisco Alves Editora. 1978.

GUIMARÃES, César. Relatório da Diretoria Geral da Instrução Pública. Arquivo do Estado de São Paulo. Livro de Ofícios de 1894 a 1896. Ordem 4992.

HERCULANO, Alexandre. O Monge de Cister. Rio de Janeiro: Tecnoprint. 1965

INFANTOSI, Ana Maria. A Escola na República Velha. São Paulo: EDEC, 1983.

KUHLMANN, Guilherme. Anuário do Ensino do Estado de São Paulo. Arquivo do Estado de São Paulo. 1922. p. 370.

MARCÍLIO, Maria Luiza. História da escola em São Paulo e no Brasil. São Paulo: Imprensa Oficial do Estado de São Paulo: Instituto Fernand Braudel. 2005.

MARX, Karl. Obras escolhidas. São Paulo: Editora Alfa-Omega. v. 1. 1982.

NAGLE, Jorge. Educação e Sociedade na Primeira República. São Paulo: EPU; Rio de Janeiro: Fundação Nacional de Material Escolar. 1974.

PÉREZ GÓMEZ, Angel. As Funções sociais da escola: da reprodução à reconstrução crítica do conhecimento e da experiência. In.: GIMENO SACRISTÁN, José; PÉREZ GÓMEZ, Angel. Compreender e transformar o ensino. 4. ed. Porto Alegre: ArtMed. 1998.

REIS FILHO, Casemiro. A Educação e a llusão Liberal: origens do ensino público paulista. Campinas: Autores Associados. 1995.

REIS JUNIOR, João Chrysostomo Bueno dos. Anuário do Ensino do Estado de São Paulo. Arquivo do Estado de São Paulo. 1910-1911. p. 82-83.

REIS JUNIOR, João Chrysostomo Bueno dos. Anuário do Ensino do Estado de São Paulo. Arquivo do Estado de São Paulo. 1914. p. 14.

ROSSI, Ednéia Regina. Espaços autônomos e modernos de educar: a instituição de ensino elementar no início da República e a produção de uma cultura escolar. In: MACHADO, Maria Cristina Gomes; OLIVEIRA, Terezinha. (Orgs.) Educação na história. São Luis, MA: Editora UEMA. 2008.

SANTOS, Alessandra de Sousa. Um dia belo, noutro esquecido: a história do Grupo Escolar Coronel Flamínio Ferreira - Limeira, São Paulo (1901-1930). (2011). Dissertação (Mestrado). 
Universidade Estadual de Campinas, Faculdade de Educação, Mestrado em Educação, Campinas.

SÃO PAULO. Decreto $n^{\circ}$ 248, de 26 de julho de 1894 - Aprova o regimento interno das Escolas Públicas. São Paulo: Assembléia Legislativa do Estado de São Paulo, Secretaria Geral Parlamentar, Departamento de Documentação e Informação, 1894. Disponível em:<http://www.al.sp.gov.br/repositorio/legislacao/decreto/1894/decreto\%20n.248,\%20de \%2026.07.1894.htm> Acesso em: 10 ago de 2012.

SÃO PAULO. Decreto $n^{\circ}$ 1.239, de 30 de setembro de 1904 - Regulamenta a Lei $n^{\circ}$ 930, de 13 de agosto de 1904. São Paulo : Assembléia Legislativa do Estado de São Paulo, Secretaria Geral Parlamentar, Departamento de Documentação e Informação, 1904a. Disponível em: <http://www.al.sp.gov.br/repositorio/legislacao/decreto/1904/decreto\%20n.1.239,\%20de\%2 030.09.1904.htm> Acesso em: 11 de ago de 2012.

SÃO PAULO. Decreto $n^{\circ}$ 1.577, de 21 de fevereiro de 1908 - Cria uma escola modelo, que servirá de padrão às escolas isoladas, a qual ficará anexa à Escola Normal. São Paulo : Assembléia Legislativa do Estado de São Paulo, Secretaria Geral Parlamentar, Departamento de Documentação e Informação, 1908. Disponível em: <http://www.al.sp.gov.br/repositorio/legislacao/decreto/1908/decreto\%20n.1.577,\%20de\%2 021.02.1908.htm> Acesso em: 11 de ago de 2012.

SÃO PAULO. Decreto 2004, de 13 de fevereiro de 1911 - Aprova o regimento interno das escolas modelos isoladas, anexas à Escola Normal de São Paulo. São Paulo : Assembléia Legislativa do Estado de São Paulo, Secretaria Geral Parlamentar, Departamento de Documentação e Informação, 1911. Disponível em:

<http://www.al.sp.gov.br/repositorio/legislacao/decreto/1911/decreto\%20n.2.004,\%20de\%2 013.02.1911.htm>.Acesso em: 11 de ago de 2012.

SÃO PAULO. Decreto 2005, de 13 de fevereiro de 1911 - Aprova e manda observar o programa de ensino para as escolas isoladas do Estado. São Paulo : Assembléia Legislativa do Estado de São Paulo, Secretaria Geral Parlamentar, Departamento de Documentação e Informação, 1911. Disponível em:

<http://www.al.sp.gov.br/repositorio/legislacao/decreto/1911/decreto\%20n.2.005,\%20de\%2 013.02.1911.htm> Acesso em: 12 de ago de 2012.

SÃO PAULO. Decreto 3.356, de 31 de maio de 1921 - Regulamenta a Lei $n^{\circ} 1.750$, de 8 de dezembro de 1920, que reforma a instrução pública. São Paulo : Assembléia Legislativa do Estado de São Paulo, Secretaria Geral Parlamentar, Departamento de Documentação e Informação, 1921. Disponível em:

<http://www.al.sp.gov.br/repositorio/legislacao/decreto/1921/decreto\%2on.3.356,\%20de\%2 031.05.1921.html> Acesso em: 12 de ago de 2012. 
SÃO PAULO. Decreto $n^{\circ}$ 3.858, de 11 de junho de 1925 - Reforma a instrução publica do Estado. São Paulo : Assembléia Legislativa do Estado de São Paulo, Secretaria Geral Parlamentar, Departamento de Documentação e Informação, 1925. Disponível em: <http://www.al.sp.gov.br/repositorio/legislacao/decreto/1925/decreto\%20n.3.858,\%20de\%2 011.06.1925.htm> Acesso em: 12 de ago de 2012.

SÃO PAULO. Lei n 930 de 13 de agosto de 1904 - Modifica várias disposições das leis em vigor sobre instrução pública do estado. São Paulo : Assembléia Legislativa do Estado de São Paulo, Secretaria Geral Parlamentar, Departamento de Documentação e Informação, 1904a. Disponível em:

<http://www.al.sp.gov.br/repositorio/legislacao/lei/1904/lei\%20n.930,\%20de\%2013.08.1904. htm> Acesso em: 11 de ago de 2012.

SÃO PAULO. Lei n ${ }^{\circ}$ 1.579, de 19 de dezembro de 1917 - Estabelece diversas disposições sobre a instrução pública do Estado. São Paulo : Assembléia Legislativa do Estado de São Paulo, Secretaria Geral Parlamentar, Departamento de Documentação e Informação, 1917. Disponível em:

<http://www.al.sp.gov.br/repositorio/legislacao/lei/1917/lei\%20n.1.579,\%20de\%2019.12.1917. htm> Acesso em: 12 de ago de 2012.

SÃO PAULO. Lei n ${ }^{\circ}$ 1.710, de 27 de dezembro de 1919 - Dispõe sobre a organização e a fiscalização do ensino. São Paulo : Assembléia Legislativa do Estado de São Paulo, Secretaria Geral Parlamentar, Departamento de Documentação e Informação, 1919. Disponível em:

<http://www.al.sp.gov.br/repositorio/legislacao/lei/1919/lei\%2on.1.710,\%20de\%2027.12.1919. htm.> Acesso em: 13 de ago de 2012.

SÃO PAULO. Lei n ${ }^{\circ} 1.750$ de 8 de dezembro de 1920 - Reforma a instrução pública do Estado. São Paulo : Assembléia Legislativa do Estado de São Paulo, Secretaria Geral Parlamentar, Departamento de Documentação e Informação, [20--]j. Disponível em: <http://www.al.sp.gov.br/repositorio/legislacao/lei/1920/lei\%20n.1.750,\%20de\%2008.12.1920 .htm> Acesso em: 13 de ago de 2012.

SAVIANI, Dermeval. Instituições Escolares no Brasil: conceito e reconstrução histórica. In: NASCIMENTO, Maria Isabel Moura; SANDANO, Wilson; LOMBARDI, José Claudinei; SAVIANI, Dermeval. (Orgs.). Instituições Escolares no Brasil: conceito e reconstrução histórica. Campinas, SP: Autores Associados. 2007. p. 3-27.

SOUZA, Rosa Fátima de. Templos de civilização: a implantação da escola primária graduada no Estado de São Paulo (1890-1910). São Paulo: Editora da UNESP. (1998).

SOUZA, Rosa Fátima de. Lições da Escola Primária. In: SAVIANI, Dermeval et al. O Legado educacional do Século XX no Brasil. 2. ed. Campinas, SP: Autores Associados. 2006. p. 109161. 
SOUZA, Rosa Fátima de. Alicerces da Pátria: história da escola primária no Estado de São Paulo (1890-1976). Campinas, SP: Mercado das Letras. 2009. 